\title{
Carbon Nanotube Fiber Pretreatments for Electrodeposition of Copper
}

\author{
Pyry-Mikko Hannula (D), ${ }^{1}$ Minttu Junnila, ${ }^{1}$ Dawid Janas, ${ }^{2}$ Jari Aromaa $\left(\mathbb{D},{ }^{1}\right.$ Olof Forsén $\left(\mathbb{D},{ }^{1}\right.$ \\ and Mari Lundström (iD) \\ ${ }^{1}$ Department of Chemical and Metallurgical Engineering, School of Chemical Engineering, Aalto University, Vuorimiehentie 2, \\ 02150 Espoo, Finland \\ ${ }^{2}$ Department of Organic Chemistry, Bioorganic Chemistry and Biotechnology, Silesian University of Technology, \\ B. Krzywoustego 4, 44-100 Gliwice, Poland
}

Correspondence should be addressed to Mari Lundström; mari.lundstrom@aalto.fi

Received 21 September 2017; Revised 3 November 2017; Accepted 3 December 2017; Published 11 February 2018

Academic Editor: Fabrizio Pirri

Copyright (C) 2018 Pyry-Mikko Hannula et al. This is an open access article distributed under the Creative Commons Attribution License, which permits unrestricted use, distribution, and reproduction in any medium, provided the original work is properly cited.

\begin{abstract}
There is increasing interest towards developing carbon nanotube-copper (CNT-Cu) composites due to potentially improved properties. Carbon nanotube macroscopic materials typically exhibit high resistivity, low electrochemical reactivity, and the presence of impurities, which impede its use as a substrate for electrochemical deposition of metals. In this research, different CNT fiber pretreatment methods, such as heat treatment, immersion in Watts bath, anodization, and exposure to boric acid $\left(\mathrm{H}_{3} \mathrm{BO}_{3}\right)$, were investigated to improve the electrochemical response for copper deposition. It was shown that these treatments affect the surface activity of CNTs, including electrical resistivity, polarization resistance, and active surface area, which influence the electrodeposition process of copper. Properties of CNT structures and CNT-Cu composites were researched by electrochemical impedance spectroscopy (EIS), galvanostatic copper deposition, scanning electron microscope (SEM), and four-point electrical resistance measurements. Heat treatment, Watts bath, anodization, and boric acid treatments were shown to be effective for modifying the CNT surface reactivity for subsequent electrochemical deposition of copper.
\end{abstract}

\section{Introduction}

The exceptional properties of carbon nanotubes (CNTs), such as stiffness, low density, high mechanical strength, and excellent electrical and thermal conductivity, have attracted researchers to utilize them in various structures. While individual nanotubes exhibit extraordinary properties, they are difficult to transfer to macroscopic CNT materials due to the existence of unoptimal contact junctions between nanotubes, warranting the research for composite structures. One particular class of such composites is based on carbon nanotubes surrounded by a copper matrix [1-3]. Low-density CNT composites with significantly increased conductivity, current-carrying capacity, and mechanical properties could revolutionize many different industry sectors with applications in electrical wiring, microelectronics, and power transfer [4-6]. Such composites can be formed by utilizing carbon nanotube wires, such as fibers or films, as the base material [7-10].

An important issue of producing CNT material on a large scale is that the manufacturing techniques generate many impurities and unwanted CNT types creating an inhomogeneous mixture of components. Undesirable impurities include, for example, soot, amorphous carbon, metal catalysts (such as $\mathrm{Fe}$ ), carbon nanoparticles, and other unwanted particles. As made, CNT structures are typically improved by procedures that clean the CNT sidewalls of unwanted impurities and add additional reactivity by modification and introduction of new functionalities, such as oxygen-containing functional groups [11, 12]. Other methods include densifying the CNT material, either by organic solvents [13] or mechanical application [14], effectively bridging the distance between individual nanotubes to decrease contact resistances. Doping with halogen gases and 
organic and ionic species have also been explored to alter the carrier density, and thus electrical resistance and activity of CNT material [15]. Modification or purification of CNT base material is routinely applied before producing composite structures [16-19].

Previously, $\mathrm{Xu}$ et al. [7] reported using anodization as a pretreatment method for producing functionalized CNT$\mathrm{Cu}$ composites. The method combined continuous fiber spinning from CNT array, fiber anodization, and finally copper deposition. The anodized CNT surfaces were shown to exhibit stronger bonding with the deposited copper compared to unanodized surfaces due to the effect of functional groups. CNT fiber coated with $1 \mu \mathrm{m}$ copper cladding after anodization resulted in a strength of about $800 \mathrm{MPa}$, whereas without anodization, the corresponding value was $611 \mathrm{MPa}$. Additionally, the conductivity of anodized CNT composite was shown to be almost four times higher. However, the effect of anodization on the electrochemical polarization of the CNT fiber was not described.

Electrochemical impedance spectroscopy (EIS) has not been conventionally applied for CNT research. However, it allows for the investigation of CNT material electrochemical properties. Properties, which affect the electrochemical reactivity, such as electrical resistivity, polarization resistance, and surface area can be compared by EIS investigation. It is important to compare these properties as pretreatment modification of CNT fiber structures is likely to affect many properties simultaneously.

The aim of this study was to investigate pretreatment methods, which can be used to positively affect the electrochemical activity of CNT material before electrochemical deposition of copper. Carbon nanotube-copper composites were also produced, and their microstructure and specific conductivity were described.

\section{Materials and Methods}

2.1. CNT Materials. Different lengths (10-350 mm) of CNT fibers and yarns were used. Diameter of fibers was $10 \mu \mathrm{m}$, while yarns were $150-200 \mu \mathrm{m}$ in diameter. CNT material consists mainly of multiwalled carbon nanotubes (MWCNTs) with a small percentage of double-walled (DWCNTs) and single-walled carbon nanotubes (SWCNTs). Yarn samples consist of a plethora of fibers rolled together and treated with acetone to densify and bundle them together to form yarns [13]. The CNT samples were produced by dry spinning directly from a CVD reactor. Pristine CNT materials were unfunctionalized and contained approximately 15\% of carbonaceous impurities and catalyst metals [12].

Macroscopic objects made of CNTs have very low weight (a fiber sample $2 \mathrm{~cm}$ in length weighs less than $10 \mu \mathrm{g}$ ), and so it is a challenging sample material to work with, easily floating or breaking. The tests were conducted by using sample holders, and the schematics are presented in Figure 1. The PVC sample holder (a) was made by gluing a copper wire to the plastic holder, and the glass-plate sample holder (b) was made with conductive Foil Shielding Tape no. 1183 (resistance $0.005 \Omega$ ) manufactured by $3 \mathrm{M}$ on the glass plate.

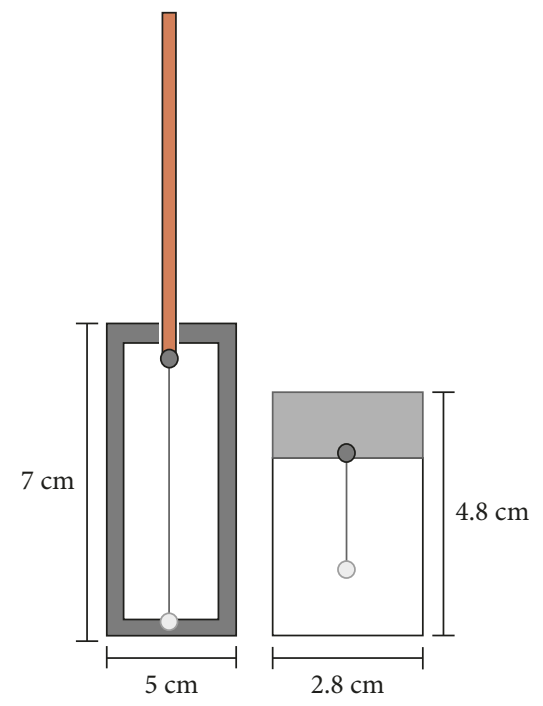

(a)

(b)

FIGURE 1: The two different sample holder setups for CNT material based on (a) PVC and (b) a glass plate.

TABLE 1: The composition of the copper deposition bath and CNT fiber pretreatment baths.

\begin{tabular}{lc}
\hline Bath & Composition \\
\hline Copper sulfate & $150 \mathrm{~g} / \mathrm{l} \mathrm{CuSO} \cdot 5 \mathrm{H}_{2} \mathrm{O}, 40.8 \mathrm{ml} / \mathrm{l} \mathrm{H} \mathrm{SO}_{4}$ \\
& $(96-98 \%)$, and $5.04 \mathrm{mg} / \mathrm{l} \mathrm{NaCl}$ \\
Watts bath & $310 \mathrm{~g} / \mathrm{l} \mathrm{NiSO} \cdot 6 \mathrm{H}_{2} \mathrm{O}, 50 \mathrm{~g} / 1 \mathrm{NiCl} \cdot 6 \mathrm{H}_{2} \mathrm{O}$, \\
Anodizing bath & and $40 \mathrm{~g} / \mathrm{l} \mathrm{H}_{3} \mathrm{BO}_{3}$ \\
Boric acid & $10 \mathrm{wt} . \% \mathrm{H}_{2} \mathrm{SO}_{4}$ \\
\hline
\end{tabular}

The electrical contact to the fiber in both sample holders was made with conductive silver paste (42469, Alfa Aesar).

2.2. Baths. Table 1 shows the employed bath compositions. Copper sulfate bath was used to electrodeposit fibers with copper. Watts bath is typically used to electrodeposit nickel, but here it was used without applied current or voltage, that is, as an immersion bath for $\mathrm{Ni}$ and $\mathrm{B}$ doping. Anodizing bath was used to electrooxidize the CNT material by anodization. Boric acid bath contains equal concentration of boric acid compared to Watts bath, in order to observe changes in CNT material by just boric acid application method. All chemicals used were of pro-analysis grade. Solutions were made in distilled water.

2.3. Electrochemical Cell Setup. Electrochemical tests were carried out using ACM Instruments Gill AC potentiostat with Gill AC Sequencer software. A standard three-electrode cell was used (Figure 2). The reference electrode was a calomel electrode (SCE, Radiometer 401) placed close to the CNT sample using a protective Schott tube with $\mathrm{Pt}$ frit (Schott B281). The anode was a copper electrode made of 0.5 $\mathrm{mm}$ thick sheet. In anodization, the counter electrode was an inert platinum electrode. 
2.4. EIS. EIS tests were carried out in copper sulfate bath before and after different treatments in order to observe changes in CNT materials. The behavior of single CNT fibers were tested as CNT fiber material is inhomogeneous and by using this method the change in properties could be reliably measured. First, the EIS measurement of a single CNT fiber was conducted in copper sulfate solution. Then, the sample was rinsed with copious amounts of water to remove electrolyte from the surface. The sample was then immersed in the studied bath or heat treated for designated time. Afterwards, the sample was lightly rinsed with deionized water by dipping into deionized water. EIS measurement was then performed again in copper sulfate solution. Thus, the effect of different treatments on the properties of a single CNT fiber in copper sulfate electrolyte could be compared pre- and posttreatments.

Electrochemical impedance spectroscopy results were presented as Bode plots. Polarization resistance, solution resistance, and capacitance were calculated with the relative change of results. Results can be compared as EIS measurements do not disturb the sample composition or properties. Solution resistance $\left(R_{\Omega}\right)$ was determined at high frequency $(100,000 \mathrm{~Hz})$. Polarization resistance $\left(R_{p}\right)$ was determined from the difference between impedance at high $(100,000 \mathrm{~Hz})$ and low frequency $(0.01 \mathrm{~Hz})$. Capacitance $\left(C_{\mathrm{dl}}\right)$ was calculated using the following equation [20]:

$$
C_{\mathrm{dl}}=\frac{\sqrt{1+R_{p} / R_{\Omega}}}{\omega_{\max } \cdot R_{p}},
$$

where $\omega_{\max }$ is the angular speed corresponding to phase angle maximum, $R_{p}$ is the polarization resistance, and $R_{\Omega}$ is the solution resistance.

2.5. CNT Material Pretreatment Methods. Heat treatment, Watts nickel bath, anodization, and boric acid treatment were investigated as potential CNT fiber activation methods. Treatment methods and parameters are listed in Table 2. The heat treatment (treatment no. 1) was carried out in furnace under oxygen flow, samples 2-6 were immersed completely in the selected solutions. In the anodization test (no. 6), CNT fiber sample was immersed in 10 wt. $\% \mathrm{H}_{2} \mathrm{SO}_{4}$ solution and anodized at $2500 \mathrm{mV}$ versus SCE for $50 \mathrm{~s}$.

2.6. Copper Deposition. Carbon nanotube fibers were electrodeposited with copper in order to estimate the kinetics of the reaction. The electrical resistance of samples was measured by four-point electrical resistance measurement (Fluke 8846a Multimeter). Copper cladding growth rates were determined as a function of current, sample length, deposition time, and copper cladding length.

\section{Results and Discussion}

3.1. Effect of CNT Pretreatment Methods. CNT materials behave as inhomogeneous resistive substrates rather than metallic substrates and exhibited significant terminal effect. The analysis by Alkire and Varjian [21] and Matlosz et al.

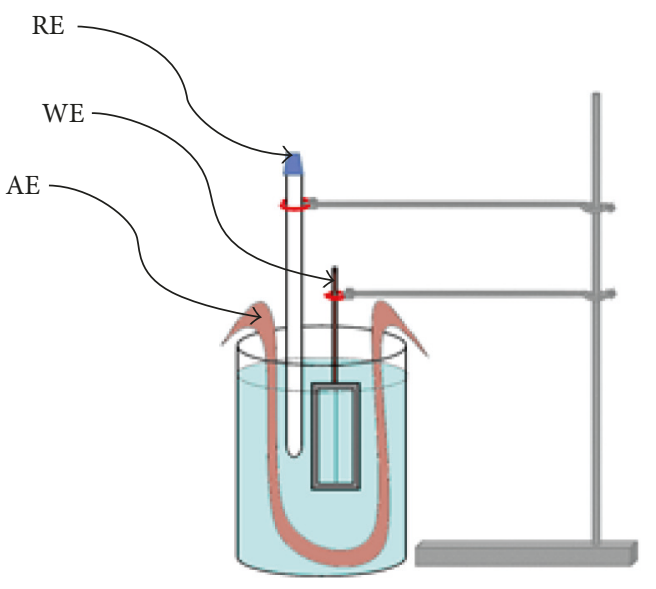

FIgURE 2: Schematics of three-electrode cell, standard calomel electrode as reference electrode (RE), CNT placed in PVC sample holder as working electrode (WE), and copper auxiliary electrode as anode (AE).

TABLE 2: Used CNT fiber pretreatment methods.

\begin{tabular}{lc}
\hline Treatment no. & Procedure \\
\hline 1 & Heat treatment, $400^{\circ} \mathrm{C}, 10 \mathrm{~min}$ \\
2 & Watts bath immersion, $72 \mathrm{~h}$ \\
3 & Watts bath immersion, $60 \mathrm{~min}$ \\
4 & Watts bath immersion, $30 \mathrm{~min}+$ rinsing \\
5 & Boric acid immersion, $60 \mathrm{~min}$ \\
6 & Anodization for $50 \mathrm{~s}, 2500 \mathrm{mV}$ versus SCE \\
\hline
\end{tabular}

[22] shows that the electrochemical copper deposition overpotentials change along electrically resistive wires. Closest to the current feed point, the activation polarization and ohmic resistance polarization are the strongest. As the distance along the wire increases, the effect of substrate resistance becomes larger causing the activation and electrolyte ohmic polarization to decrease. After a certain distance, the driving force of the deposition, that is, the activation overpotential, becomes too small to support deposition. This effect is decreased during electrodeposition, when the growing metal on the surface of the substrate provides additional conductivity and thus the deposition can progress further. Thus, the copper growth on CNT fibers progresses further from close to the electrical contact as the deposition is continued. Improving the conductivity and activity of the substrate through pretreatments is expected to increase this deposition speed. The effect of different pretreatment methods on these surface properties were studied using electrochemical impedance spectroscopy (EIS). Table 3 shows the relative changes in the CNT fiber polarization resistance, solution resistance, and capacitance based on EIS results after different treatments.

The following reasoning was used to analyze the results: The polarization resistance is a measure of the CNT surface that supports charge-transfer reaction for copper deposition. The ohmic resistance describes sample resistivity, but it includes both the sample resistance and the uncompensated solution resistance. The uncompensated resistance was not 
TABLE 3: EIS measured relative changes in polarization resistance, ohmic resistance, and capacitance of CNT fiber samples after treatments.

\begin{tabular}{lcccc}
\hline Sample & Treatment & Polarization resistance $\left(\Delta R_{p}, \Omega \cdot \mathrm{cm}^{2}\right)$ & Ohmic resistance $\left(\Delta R_{\Omega}, \Omega\right)$ & Capacitance $\left(\Delta C_{\mathrm{dl}}, \mu \mathrm{F} / \mathrm{cm}^{2}\right)$ \\
\hline 1 & Heat treatment & $4 \cdot 10^{-5}$ & 0.03 & $2 \cdot 10^{-5}$ \\
2 & Watts bath $72 \mathrm{~h}$ & $5 \cdot 10^{-5}$ & 0.004 & $1.9 \cdot 10^{-5}$ \\
3 & Watts bath 60 min & $6.9 \cdot 10^{-4}$ & 0.16 & $1.9 \cdot 10^{-5}$ \\
4 & Watts bath 30 min + rinsing & 0.03 & 0.63 & $1 \cdot 10^{-3}$ \\
5 & Boric acid 60 min & 0.01 & 0.9 & 3.7 \\
6 & Anodization & 0.16 & 2.6 & 4 \\
\hline
\end{tabular}

considered significant because of concentrated test solutions, small distance between reference electrode and sample, and small applied currents. The measured capacitance results from the adsorbed species in the electrochemical double layer. The capacitance was considered to describe the electrochemically active area. Changes in the measured capacitance can result from a variety of causes, which change the surface area of CNT fibers.

Relative resistance change $\Delta R_{p}<1$ indicates improved CNT surface activity, and relative ohmic resistance $\Delta R_{\Omega}<1$ indicates improved conductivity, whereas values above 1 for $\Delta R_{p}$ and $\Delta R_{\Omega}$ indicate impaired properties. If relative value of $C_{\mathrm{dl}}$ was $<1$, the active area was reduced and if $C_{\mathrm{dl}}$ was $>1$, the active area had increased. The typical double layer capacitance of metals and CNT in electrolyte is about the same, about $10-50 \mathrm{mF} / \mathrm{cm}^{2}$, and the capacitance value can be used as a measure of electrochemically active area $[23,24]$. As the polarization resistance $\left(\Omega \cdot \mathrm{cm}^{2}\right)$ and capacitance $\left(\mathrm{F} / \mathrm{cm}^{2}\right)$ have opposite relation to surface area, the relative changes can be used to estimate if the changes result from surface activation or surface area changes.

From Table 3, it can be observed that the heat treatment strongly affects both the polarization resistance and solution resistance of the sample (sample 1). This indicates the positive effect of heat treatment on CNT surface activity and conductivity. This result is attributed to the small amount of functional groups generated during mild heat treatment at low temperatures and the removal of less-conductive amorphous carbon particles. The decrease in capacitance indicates decreased active area, possibly due to removal of large impurity particles. The decrease in both polarization resistance and capacitance indicates that while the total surface area was decreased, the surface was more active due to the decrease in resistance and addition of oxygen-containing functional groups.

The purpose of the immersion in the Watts bath was to dope the CNT material surface with $\mathrm{Ni}$ and $\mathrm{B}$. The effect of Watts bath treatment was shown to activate CNT surface significantly (samples 2, 3 and 4), similarly to heat treatment. The Bode plot of EIS before and after Watts bath immersion for fiber sample 3 is shown in Figure 3. After 60-minute immersion in Ni- and B-containing bath, the ohmic resistance decreased to $16 \%$ of the original value indicating improved conductivity of CNTs as noted previously for CNTs and graphene [25-27]. The decrease in polarization resistance indicates activation of the CNT fiber surface by providing more electrochemically active sites. The capacitance decreased, indicating a decrease of active surface area. The immersion time also had an effect; during longer times,

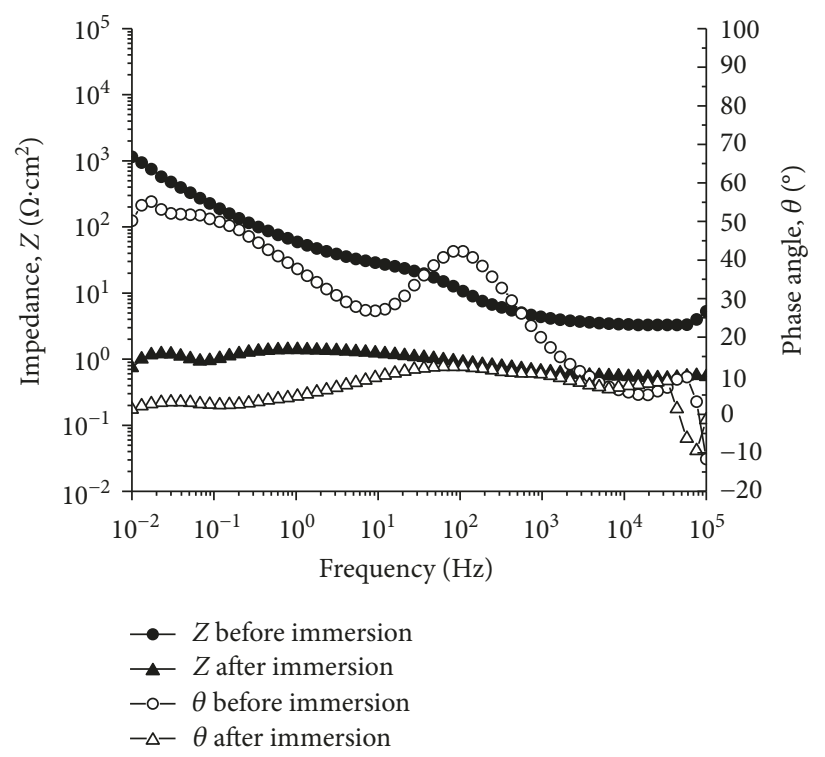

FIGURE 3: Impedance and phase angle before and after Watts bath immersion (fiber sample 3).

the fiber was doped more heavily, leading to more pronounced decrease in ohmic resistance and polarization resistance. This result is further confirmed by rinsing the sample with copious amounts of water after immersion in Watts bath (sample 4), which then produced much smaller effect. This result stems from the removal of activity and conductivity increasing dopants. The improved electrochemical response of CNT fibers immersed in Watts bath before electrodeposition is also shown later by galvanostatic copper deposition tests (Figure 7).

EIS for sample 5 before and after boric acid immersion is shown in Figure 4. This test was conducted to observe the changes made by $\mathrm{B}$ doping only. In our case, the resistivity of CNT fiber was only slightly decreased after B doping due to the small immersion time and low concentration of boric acid. However, the impedance and phase angle were reduced and polarization resistance decreased significantly after boric acid treatment. Analogous to our work, CNTs doped with boron have shown increased electrochemical activity for oxygen reduction reaction [28]. Based on the pretreatment results by Watts bath and boric acid, it can be concluded that both $\mathrm{Ni}$ and $\mathrm{B}$ doping showed an improvement in increasing the electrochemical reactivity of CNT material. Doping with both elements simultaneously and for longer times (until $72 \mathrm{~h}$ ) gave the best results. 


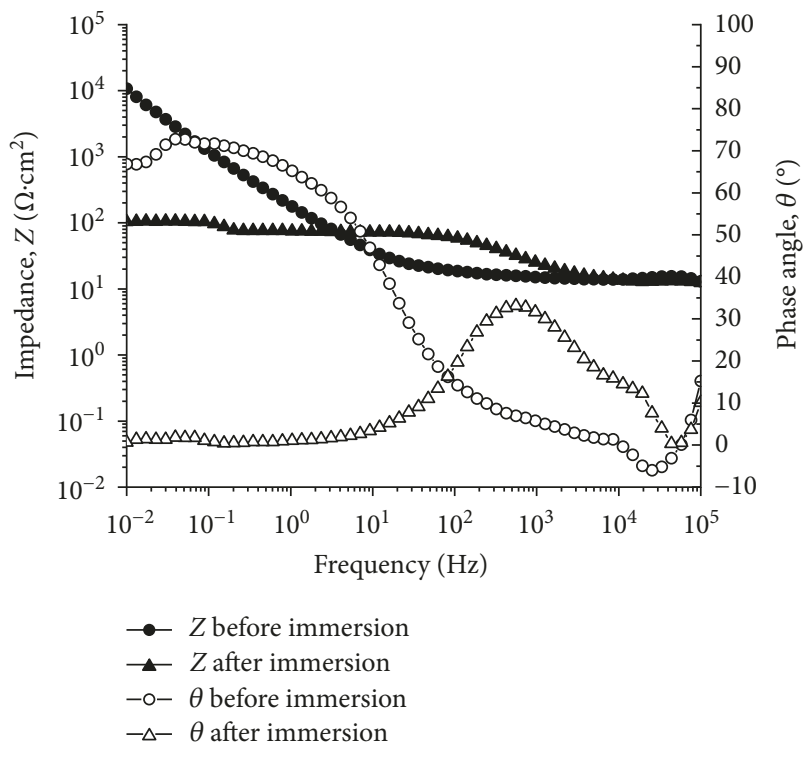

Figure 4: Impedance and phase angle spectrums before and after immersion in boric acid (sample 5).

Anodization at $2.5 \mathrm{~V}$ versus SCE is a highly oxidizing procedure that strongly affects the surface structure of nanotube material, sample 6 . Strong anodization introduced oxygen-containing functional groups at the CNT material surface, which then reduced the charge-transfer resistance of the CNT fiber [16]. At the same time, the sample resistance increased as the anodization process was so severe that the mean free path of electrons was decreased due to deterioration of nanotube sidewalls [29]. Finally, the active surface area of the fiber increased considerably likely due to the decrease in hydrophobicity by large additions of functional groups.

3.2. Electrochemical Deposition for CNT-Cu Production. CNT$\mathrm{Cu}$ composite samples were produced by electrodeposition on CNT yarns in copper sulfate electrolyte (Figure 5). Samples were produced up to 30 centimeters in length with a typical diameter of approximately $150 \mu \mathrm{m}$. Density of produced composite samples varied from 3.0 to $6.5 \mathrm{~g} / \mathrm{cm}^{3}$, increasing with the amount of copper deposited. Samples in Figures 5(b) and 5(c) were fractured by bending to observe the composite wire insides. The surface of yarns was covered by a continuous copper cladding, while copper also penetrated inside the CNT material (Figure 5(c)).

The specific electrical conductivities of produced composite samples are shown in Figure 6. Specific conductivities normalized by the sample weight were used as the crosssectional area of CNT material and resulting composite are never uniform. The specific conductivity of pristine CNT yarns is also shown for comparison (data point at $100 \mathrm{wt} . \%$ $\mathrm{CNT}$ ). The specific conductivity of CNT-Cu composites strongly increases with the amount of copper. The conductivity is increased approximately tenfold when comparing $5 \mathrm{wt}$ \% CNTs to the pure CNT yarn. The results are in line with the previously published values of CNT-Cu wires
$[7,9,10]$ The specific conductivity reported here decreases less as the weight percentage of CNTs increases compared with thinner fibers [10]. This result is attributed to the difficulty of depositing continuous copper layers inside thick and dense yarn matrices. Thus, in comparison, more copper is deposited as a continuous cladding on top of the yarn surface leading to an improvement in the electrical conductivity.

Finally, galvanostatic deposition tests were performed on carbon nanotube fibers. Due to the previously mentioned terminal effect causing the localized plating phenomenon on CNT fibers, the plating speed could be determined. Deposition speed rate is calculated from optical microscopy inspection of deposit length after deposition test. First, CNT fibers were deposited at varying applied current to observe the plating kinetics of nonmodified materials. Then, the fiber samples were pretreated by immersion in Watts bath for 60 minutes before copper deposition. This test was conducted twice to confirm the effect of Watts bath. The plating rate results are shown in Figure 7 . It was observed that the highest coating rates were for samples immersed in Watts bath, confirming the results from EIS measurements. At the same applied potential, the deposition speed was approximately five times higher for Watts bath-pretreated samples. The deposition speed was higher at over 10 times less applied current, exhibiting the powerful effect of Ni and B doping provided by the Watts bath immersion. Similar copper deposition enhancement has been shown for oxygenfunctionalized CNT materials elsewhere [16].

In conclusion, we studied improving the electrochemical deposition of copper on CNT fibers by various treatments. These treatments changed the conductivity, polarization resistance, and active surface area of the samples. The copper deposition rate was enhanced considerably by $\mathrm{Ni}$ and $\mathrm{B}$ doping from Watts bath without the need for harsh treatments, such as oxidation, that are known to deteriorate the nanotube properties [29]. Previously, similar improvements in enhancing the copper deposition rate on CNT macrostructures have been attained by utilizing harsh oxidation as a pretreatment method $[7,16]$. In this case, we used a "soft" doping method, which had a positive effect on the CNT material conductivity. The specific conductivity of thick CNT-Cu yarn composites (90\% of $\mathrm{Cu}$ at ca. 5 wt.\% CNTs) decreased less than previously shown [10] thinner CNT-Cu fibers (50\% of $\mathrm{Cu}$ at ca. 5 wt.\% CNTs), likely due to less penetration of copper inside the thick CNT matrix.

\section{Conclusion}

Carbon nanotube (CNT) fibers were pretreated by various solutions and oxidative treatments. These treatments were shown to change the electrochemical response of CNT fibers for copper deposition. Surface properties of CNT fibers were characterized by electrochemical impedance spectroscopy (EIS) to observe changes in polarization resistance, ohmic resistance, and capacitance. The deposition rates of pristine and Watts bath-immersed samples were compared by galvanostatic copper deposition and it was found that the deposition rate increased drastically with pretreatment in Watts 


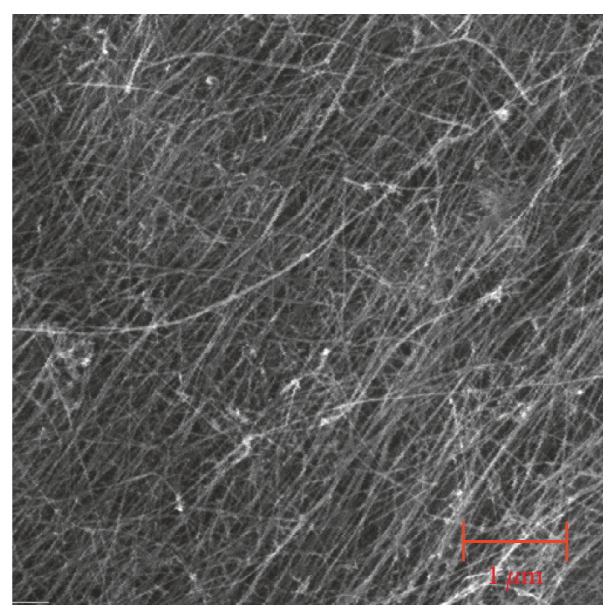

(a)

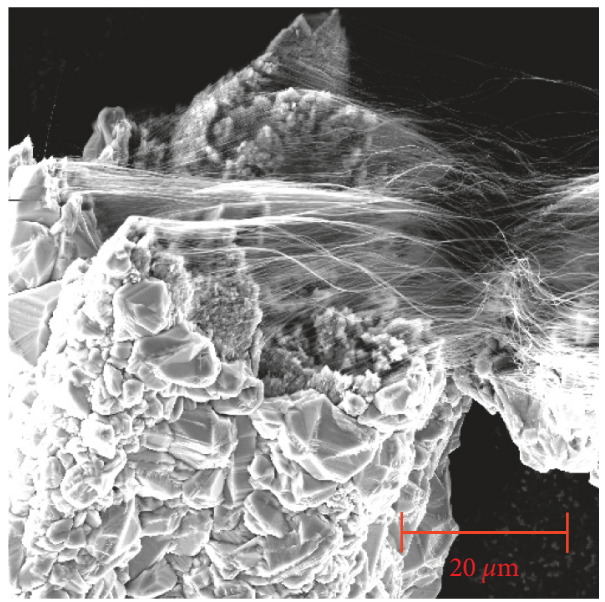

(c)

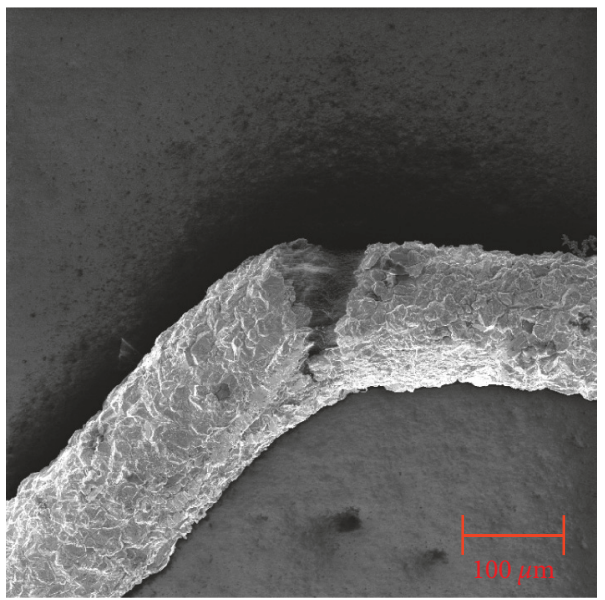

(b)

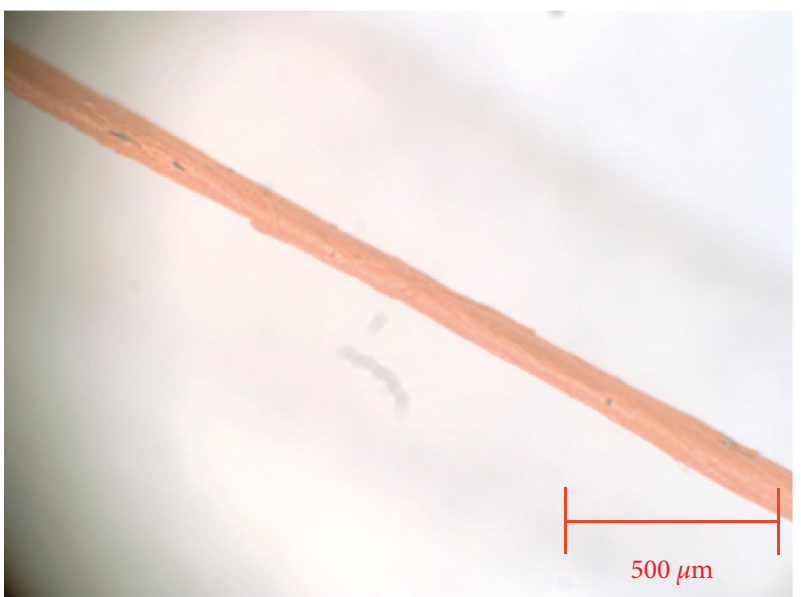

(d)

Figure 5: CNT yarn. (a) CNT morphology before Cu deposition, (b) SEM image of fractured CNT-Cu composite, (c) close-up of fractured composite cross section showing CNTs protruding from surrounding copper, and (d) optical microscope image of composite surface.

bath as predicted by EIS measurements. The specific electrical conductivity of carbon nanotube-copper composite samples with various CNT wt.\% were reported. The highest specific conductivity was found to be at $87 \mathrm{wt} . \%$ of copper at $4.7 \mathrm{wt} . \%$ of CNTs. The results show that the pretreatments can be used to tune the electrochemical response of CNT fibers for copper deposition. Simple immersion in Watts bath before deposition was shown to increase the deposition rate on CNT fibers by approximately fivefold. The study demonstrated that with careful optimization, it is possible to obtain CNT-Cu composites at a high rate. As indicated by the literature, such materials $(\mathrm{Cu}$ reinforced with nanocarbon) could show improved electrical, thermal, or mechanical properties as compared with pure copper. Further experiments are under way to determine it.

\section{Conflicts of Interest}

The authors declare that they have no conflicts of interest.

\section{Acknowledgments}

This work has been supported by the FP7 FundRef identification ID: European project Ultrawire (Grant Agreement 609057) and by the Finnish Academy NoWaste project FundRef identification ID: (Grant Agreement 297962). RawMatTERS Finland Infrastructure (RAMI) supported by the Academy of Finland is greatly acknowledged. Dawid Janas would like to thank the National Science Center, Poland (under the Polonez program, Grant Agreement UMO-2015/19/P/ST5/03799) and the European Union's Horizon 2020 Research and Innovation Programme (Marie Sklodowska-Curie Grant Agreement 665778). Dawid Janas would also like to acknowledge Foundation for Polish Science for START scholarship (START 025.2017) and the Silesian University of Technology in Gliwice for funding the research in the framework of habilitation grant (04/020/RGH17/0050). 


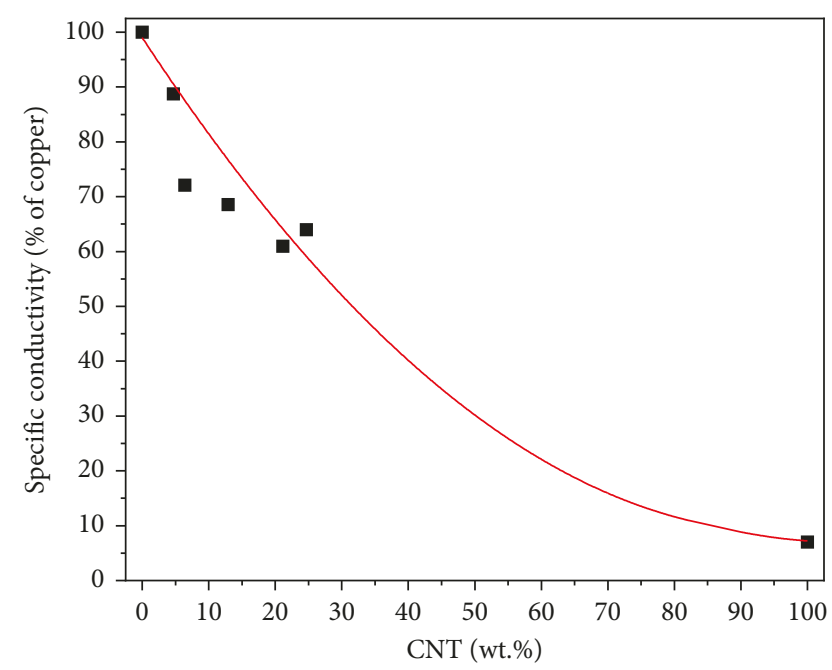

Figure 6: Specific conductivity of CNT-Cu composites prepared by electrodeposition on CNT yarns as a function of CNT wt.\%. Pure copper and pristine CNT yarn conductivity is also shown for comparison.

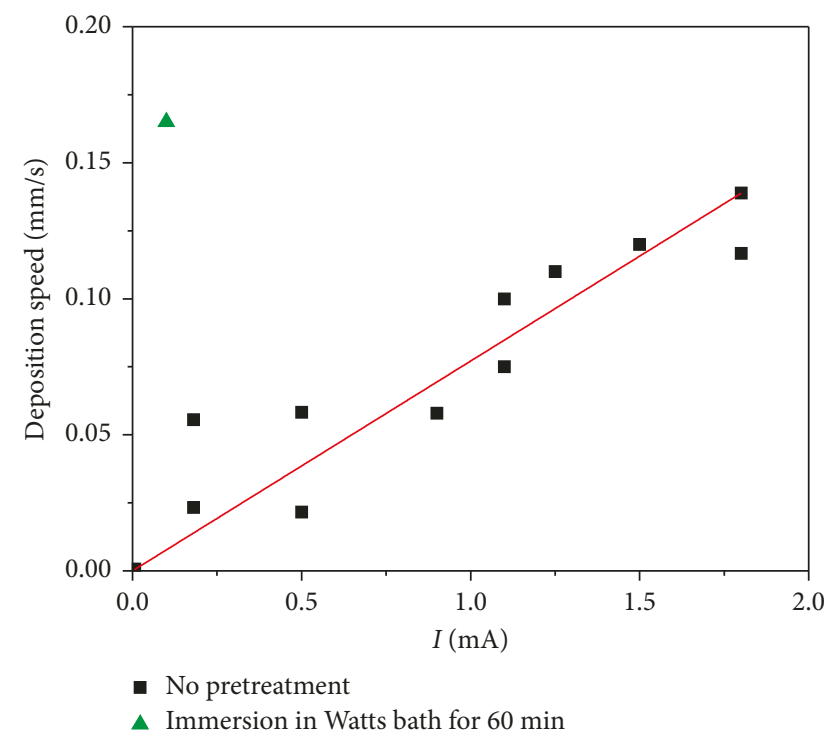

FIgURE 7: Copper coating rate on CNT fibers in copper sulfate electrolyte. Modified from [10] with additional data.

\section{References}

[1] S. Bakshi, D. Lahiri, and A. Agarwal, "Carbon nanotube reinforced metal matrix composites-a review," International Materials Reviews, vol. 55, no. 1, pp. 41-64, 2010.

[2] O. Hjortstam, P. Isberg, S. Söderholm, and H. Dai, "Can we achieve ultra-low resistivity in carbon nanotube-based metal composites?," Applied Physics A, vol. 78, no. 8, pp. 1175-1179, 2004.

[3] D. Janas and B. Liszka, "Copper matrix nanocomposites based on carbon nanotubes or graphene," Materials Chemistry Frontiers, vol. 2, pp. 22-35, 2018.

[4] C. Subramaniam, A. Sekiguchi, T. Yamada, D. N. Futaba, and K. Hata, "Nano-scale, planar and multi-tiered current pathways from a carbon nanotube-copper composite with high conductivity, ampacity and stability," Nanoscale, vol. 8, no. 7, pp. 3888-3894, 2016.

[5] Y. Chai, P. C. Chan, Y. Fu, Y. Chuang, and C. Liu, "Copper/carbon nanotube composite interconnect for enhanced electromigration resistance," in Proceedings of 58th Electronic Components and Technology Conference (ECTC'08), p. 412, Lake Buena Vista, FL, USA, May 2008.

[6] C. Subramaniam, T. Yamada, K. Kobashi et al., "One hundred fold increase in current carrying capacity in a carbon nanotube-copper composite," Nature Communications, vol. 4, p. 2202, 2013.

[7] G. Xu, J. Zhao, S. Li, X. Zhang, Z. Yong, and Q. Li, "Continuous electrodeposition for lightweight, highly conducting and strong carbon nanotube-copper composite fibers," Nanoscale, vol. 3, no. 10, pp. 4215-4219, 2011.

[8] S. Ganguli, A. Reed, C. Jayasinghe et al., "A simultaneous increase in the thermal and electrical transport in carbon nanotube yarns induced by inter-tube metallic welding," Carbon, vol. 59, pp. 479-486, 2013.

[9] L. K. Randeniya, A. Bendavid, P. J. Martin, and C. Tran, "Composite yarns of multiwalled carbon nanotubes with metallic electrical conductivity," Small, vol. 6, no. 16, pp. 1806-1811, 2010.

[10] P. Hannula, A. Peltonen, J. Aromaa et al., "Carbon nanotubecopper composites by electrodeposition on carbon nanotube fibers," Carbon, vol. 107, pp. 281-287, 2016.

[11] R. Saito, G. Dresselhaus, and M. Dresselhaus, Physical Properties of Carbon Nanotubes, Imperial College, London, UK, 1998.

[12] Y. L. Li, I. A. Kinloch, and A. H. Windle, "Direct spinning of carbon nanotube fibers from chemical vapor deposition synthesis," Science, vol. 304, no. 5668, pp. 276-278, 2004.

[13] S. Tawfick, Z. Zhao, M. Maschmann et al., "Mechanics of capillary forming of aligned carbon nanotube assemblies," Langmuir, vol. 29, no. 17, pp. 5190-5198, 2013.

[14] J. Alvarenga, P. R. Jarosz, C. M. Schauerman et al., "High conductivity carbon nanotube wires from radial densification and ionic doping," Applied Physics Letters, vol. 97, no. 18, p. 182106, 2010.

[15] L. Duclaux, "Review of the doping of carbon nanotubes (multiwalled and single-walled)," Carbon, vol. 40, no. 10, pp. 1751-1764, 2002.

[16] P. Hannula, J. Aromaa, B. P. Wilson et al., "Observations of copper deposition on functionalized carbon nanotube films," Electrochimica Acta, vol. 232, pp. 495-504, 2017.

[17] E. Titus, N. Ali, G. Cabral, J. Gracio, P. R. Babu, and M. Jackson, "Chemically functionalized carbon nanotubes and their characterization using thermogravimetric analysis, fourier transform infrared, and Raman spectroscopy," Journal of Materials Engineering and Performance, vol. 15, no. 2, pp. 182-186, 2006.

[18] S. I. Cha, K. T. Kim, S. N. Arshad, C. B. Mo, and S. H. Hong, "Extraordinary strengthening effect of carbon nanotubes in metal-matrix nanocomposites processed by molecularlevel mixing," Advanced Materials, vol. 17, no. 11, pp. 13771381, 2005.

[19] Y. Yang, Y. Wang, Y. Ren et al., "Single-walled carbon nanotube-reinforced copper composite coatings prepared by electrodeposition under ultrasonic field," Materials Letters, vol. 62, no. 1, pp. 47-50, 2008.

[20] R. G. Kelly, J. R. Scully, D. Shoesmith, and R. G. Buchheit, Electrochemical Techniques in Corrosion Science and Engineering, CRC Press, Boca Raton, FL, USA, 2002. 
[21] R. Alkire and R. Varjian, "Resistive wire electrodes," Journal of the Electrochemical Society, vol. 121, no. 5, pp. 622-631, 1974.

[22] M. Matlosz, P. Vallotton, A. West, and D. Landolt, "Nonuniform current distribution and thickness during electrodeposition onto resistive substrates," Journal of the Electrochemical Society, vol. 139, no. 3, pp. 752-761, 1992.

[23] S. Shiraishi, H. Kurihara, K. Okabe, D. Hulicova, and A. Oya, "Electric double layer capacitance of highly pure single-walled carbon nanotubes $\left(\mathrm{HiPco}^{\mathrm{TM}}\right.$ Buckytubes $^{\mathrm{TM}}$ ) in propylene carbonate electrolytes," Electrochemistry Communications, vol. 4, no. 7, pp. 593-598, 2002.

[24] E. Frackowiak, K. Jurewicz, S. Delpeux, and F. Béguin, "Nanotubular materials for supercapacitors," Journal of Power Sources, vol. 97-98, pp. 822-825, 2001.

[25] J. Lu, X. Zhang, X. Wu, Z. Dai, and J. Zhang, “A Ni-doped carbon nanotube sensor for detecting oil-dissolved gases in transformers," Sensors, vol. 15, no. 6, pp. 13522-13532, 2015.

[26] K. C. Kwon, K. S. Choi, C. Kim, and S. Y. Kim, "Effect of transition-metal chlorides on graphene properties," Physica Status Solidi (A), vol. 211, no. 8, pp. 1794-1800, 2014.

[27] B. Wei, R. Spolenak, P. Kohler-Redlich, M. Rühle, and E. Arzt, "Electrical transport in pure and boron-doped carbon nanotubes," Applied Physics Letters, vol. 74, no. 21, pp. 3149-3151, 1999.

[28] Y. Zhao, L. Yang, S. Chen et al., "Can boron and nitrogen codoping improve oxygen reduction reaction activity of carbon nanotubes?" Journal of the American Chemical Society, vol. 135, no. 4, pp. 1201-1204, 2013.

[29] J. E. Moreno Marcelino, E. Vigueras Santiago, G. Lopez-Tellez, and S. Hernández López, "Chemical functionalization of carbon nanotubes and its effects on electrical conductivity," Journal of Nano Research, vol. 28, pp. 51-61, 2014. 


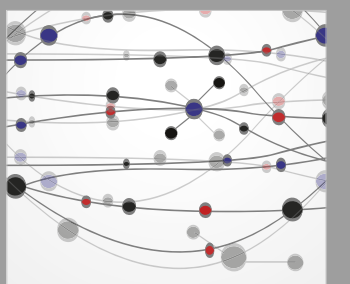

The Scientific World Journal
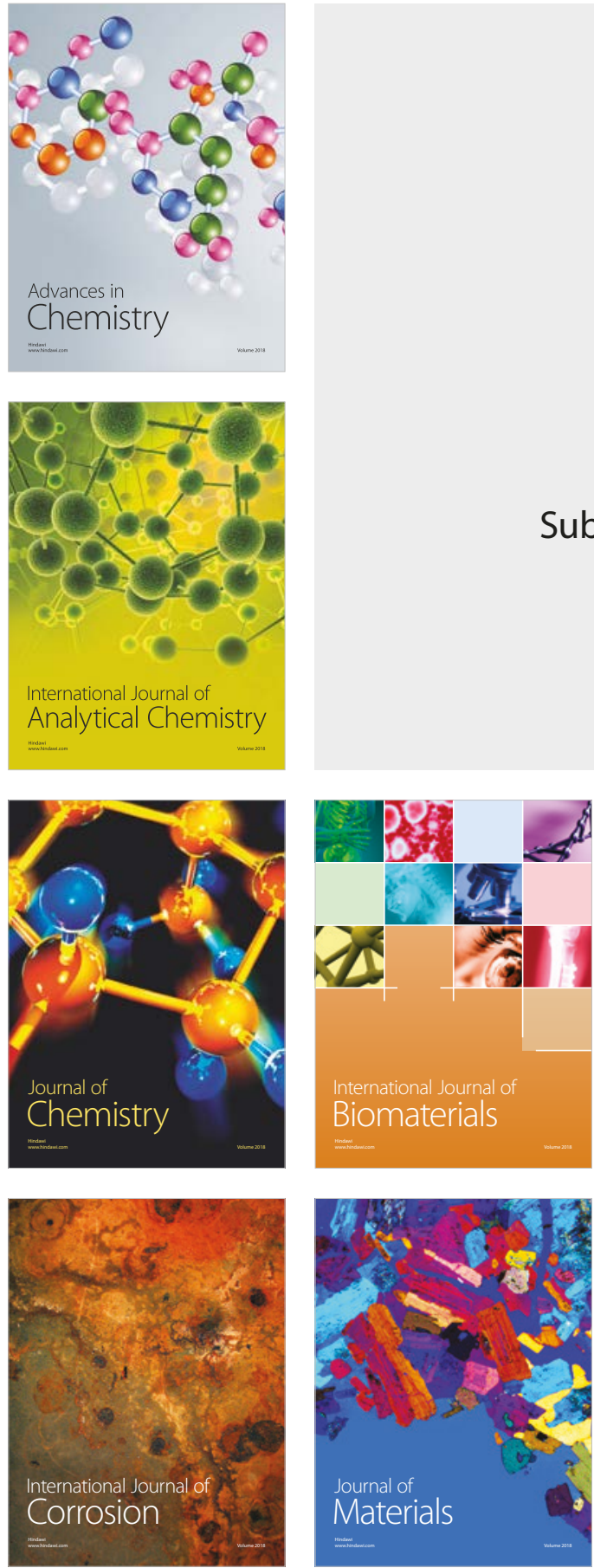

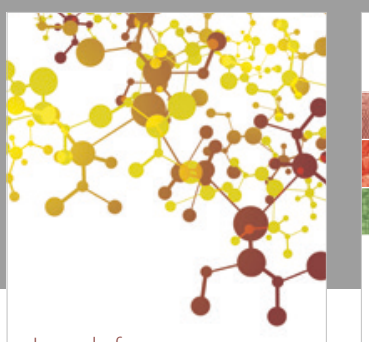

Journal of

Applied Chemistry
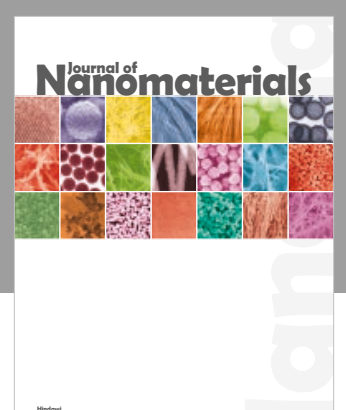

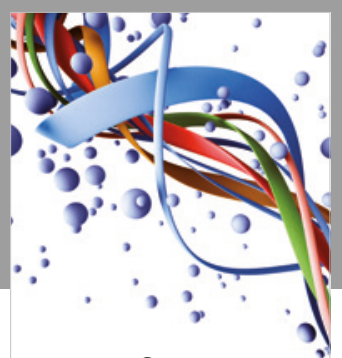

Scientifica

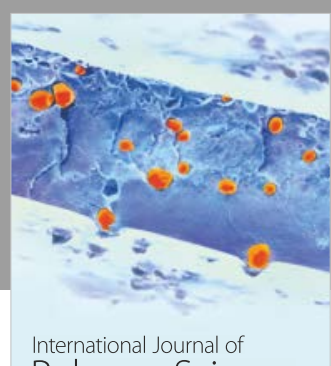

Polymer Science

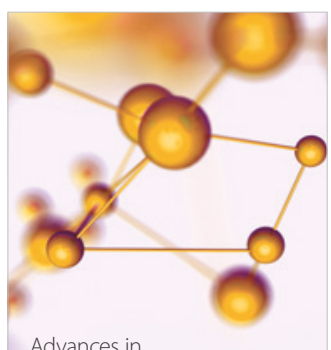

Physical Chemistry
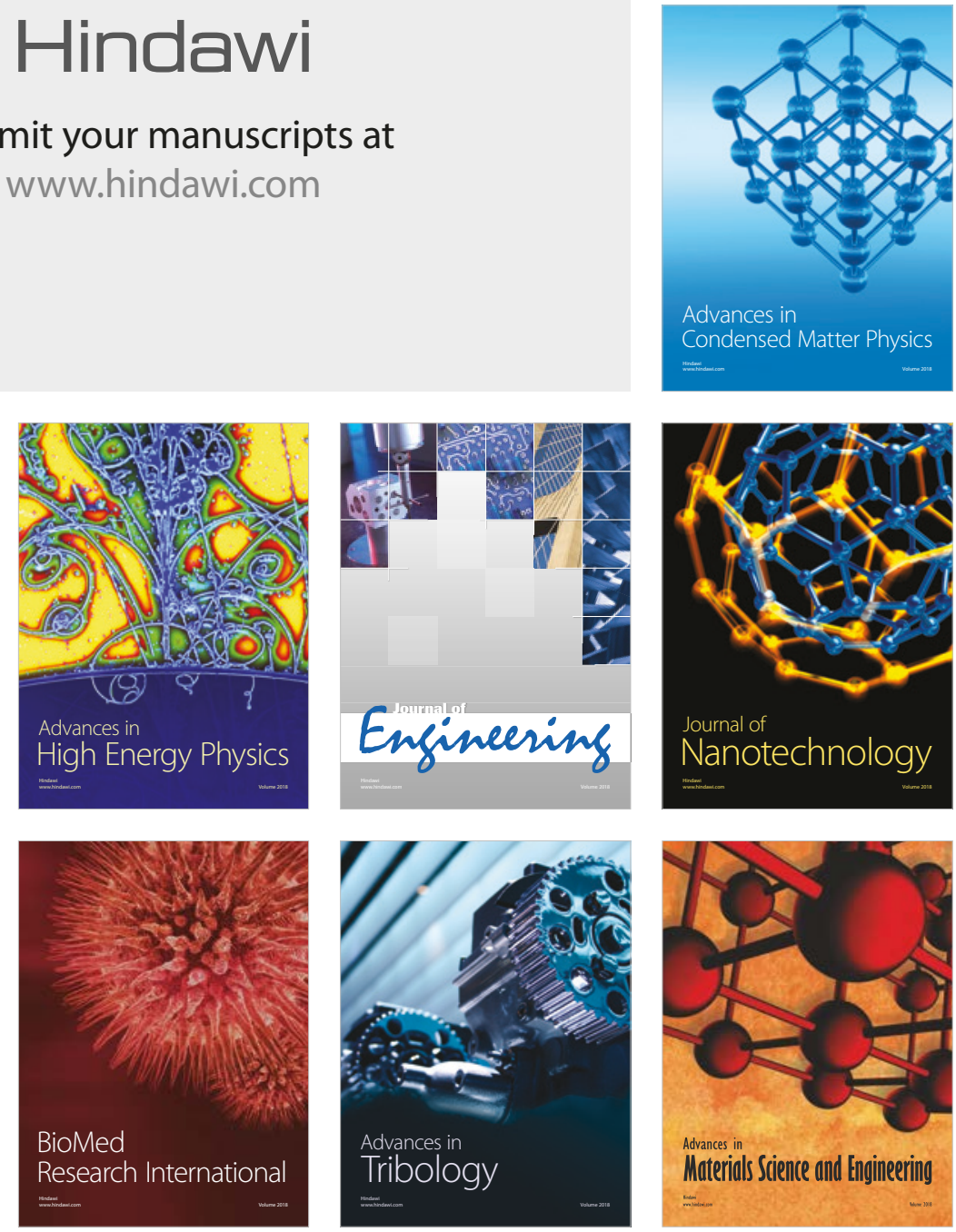